\title{
THE STOCKHOLM NEONATAL FAMILY-CENTERED CARE STUDY: EFFECTS ON SALIVARY CORTISOL IN INFANTS AND THEIR MOTHERS
}

\author{
E. Mörelius ${ }^{1}$, E. Berggren Broström ${ }^{2}$, B. Westrup ${ }^{2}$, I. Sarman ${ }^{3}$, A. Örtenstrand ${ }^{2}$ \\ ${ }^{I}$ Department of Social and Welfare Studies, Faculty of Health Sciences, Linköping University, Norrköping, \\ ${ }^{2}$ Department of Woman and Child Health, Karolinska Institutet and University Hospital, ${ }^{3}$ Department of \\ Clinical Science and Education, Södersjukhuset, Karolinska Institute, Stockholm, Sweden
}

Objective: Parental involvement in the care of preterm infants in neonatal intensive care units (NICUs) is common, but little is known about stress responses in mothers and infants.

Aim: To evaluate the effect of family-centered care on salivary cortisol reactivity in mothers and infants and the correlation between the mothers' and the infants' salivary cortisol.

Method: This study is part of a randomized controlled trial conducted at two level-II NICUs, including Family Care (FC), where parents were able to stay 24 hours/day from admission to discharge, and Standard Care (SC). To investigate the cortisol response, saliva was collected from 289 preterm infants and their mothers before and after a diaper change at the time of discharge.

Result: No significant differences were found between the two groups in baseline or response cortisol concentrations, either in mothers or in infants. The results revealed a correlation between preterm infants' and their mothers' baseline and response cortisol in the FC group: $r=0.31(p=0.001)$ and $r=0.24(p=0.01)$, respectively. Such correlation was not observed in the SC group: $r=0.14(p=0.14)$ and $r=0.18(p=0.07)$, respectively.

Conclusion: Parents' presence throughout the hospital stay may accelerate the relationship of the motherinfant dyad and improve their ability to follow each other's cortisol rhythm. The significance of the measured cortisol levels is still unclear, but this model of FC may have a positive impact on the attachment process. 